\title{
How Dangerous is the Web for Creative Work?
}

\author{
Hermann Maurer, Rizwan Mehmood and Petra Korica-Pehserl \\ Graz University of Technology, Austria
}

\begin{abstract}
With the rapid penetration of the Web into all areas of society there is also an increasing number of warning voices that the Web is endangering creative work: it encourages plagiarism, the spreading of half-truths, causes loss of memorizing ability, reduces the ability to read complex matters, provides so many distractions that prevent coherent thinking, networks of pseudo-friends eat up valuable productive time, etc. One early target of complaints were search engines with which we "build up a distorted reality", this was followed by researchers who seemed to show the rather negative effects of new (social media) on "reading with understanding", and it has culminated in a number of publications showing negative effects of many aspects of the internet including scathing attacks on e-Learning, like in the German book by Manfred Spitzer on "Digital Dementia: How we make sure that all of us are getting stupid". In this paper we discuss how the Web both supports and stifles creative activities. We report on our experiences, many based on a project that was part of the "Sparkling Science" initiative of the Austrian Federal Ministry for Science and Research. We show that some claims can be validated, others are exaggerated.
\end{abstract}

Keywords: Web, creativity, social networks, skills, internet dangers

\section{Introduction}

Everybody agrees that the Web (and mobile devices) have changed the fabric of our society in an essential way. It will continue to do so, and not just concerning the aspects we mention in the abstract, but also many others, such as the "Big Brother" syndrome, a change of lifestyle, morals, e-learning, and much more, like even warfare. We have addressed the general situation in a paper Maurer 2013 [1]. In the current paper we concentrate on the effect of features of the Web on reading, writing, understanding and creative work, and how some features (like collaboration or beyond-the-text media) can both help and be detrimental. The hype surrounding this ranges from "all information at our finger tips", "the wisdom of crowds", "crowdsourcing solves problems unthinkable before", "social networks add to the value of our lives", "democracy has finally arrived", "everyone can now be a publisher", "learning as we know it is changing dramatically" or "everything we need to know we can find now in Wikipedia", etc.

There are also success stories that are a bit more ambivalent, and it is worth to consider some of them: "Wikipedia has wiped out classical encyclopaedias". This is more or less true, if one sees the desperate struggles of formerly leading encyclopaedias like the English Britannica and the German Brockhaus: event they try to get now most of their revenues from electronic versions, desperately trying to support an editorial team that provides more up to date and even more reliable information than Wikipedia. Britannica is offering a basic service for free, but full access ("premium service") by subscription only [2]. Brockhaus is also working with a payment model and is mainly surviving by analysing what typical students need, i.e. not a plethora of distributed information but well-structured longer expositions on "all topics of interest" [3], [4]. There are other attempts, particularly more regional servers such as e.g. the Austria-Forum [5] and the Serbia-Forum [6] where the first author is involved in personally, or special types of encyclopaedias arising due to the nature of an institution. A good example is the Smithonian in Washington that is receiving a stream of queries all the time and has decided to make answers available to the public [7]. Overall, the wealth of information on Wikipedia is unprecedented, yet whether a single player should 
dominate the field with no clear transparent editorial policies or known specialists behind it is of concern to some.

While we have so far basically only discussed text-based services, we also have to take into account the emergence of huge on-line databases with multi-media material like WikiCommons, Flickr, Instagramm plus scores of other pictureor animated picture applications that are also trying to seduce persons to share pictures, often artificially enhanced, like Gifboom, Cinemagram, Flixel, Vine, Tout, Viddy and Keek. Sharing photos via social media has become routine, YouTube and similar video or audio-clip services are booming, and one must not forget the Linked Open Data Initiative that allows the publication and semantic-enabled linking between content of different content providers. Many libraries have started to release data about publications in Linked Data formats: Among many others, the Open Library [8], as an "open, editable library catalog", building towards a Web page for every book ever published, makes about 20 million book description in RDF available, more than a million with searchable full text. Much material where the copyright has expired is now available, mostly even free, over the Web, due to massive digitalization efforts of leading libraries, of Google, and of others. But also a good part of currently published works is available in the form of e-Books on various readers, from Tablet PCs to Amazon's Kindle.

Taking all those massive amounts of information/knowledge available on the Web, free or inexpensive, together with the effortless collaboration via social networks or discussion groups, we have the reason why a naïve approach may come to the conclusion: mankind has never been better equipped to work with huge amounts of material and extracting and extending knowledge in whatever discipline, opening a new era of creativity.

However, the situation is less rosy, as we will explain in the next sections.

\section{Modern Media May Decrease Our Mental Powers}

There has been concern, first voiced clearly and with some data to prove the point in [9] that modern media, particularly networked computers are endangering our capacity to think, to remember clearly, and to read and write with concentration. On the cover of Brabazon's book you find the provocative statement "Looking at schools and universities, it is difficult to pinpoint when education, teaching and learning started to haemorrhage purpose, aspiration and function. As the internet offers a glut of information, bored surfers fill their cursors and minds with irrelevancies, losing the capacity to sift, discard and judge."

It is interesting to note that this was written two years after the euphoric book on "the wisdom of crowds" [10] by Surowiecki, yet in the same year 2007 when the book by Brabazon appeared, Andrew Keen answered Surowiecki with his (partly tongue-in-cheek) book [11]. Again, to get an impression of the book, two quotes will help: "How blogs, MySpace, YouTube, and the rest of today's user-generated media are destroying our economy, our culture, and our values. .." or "Instead of creating masterpieces, millions of 'monkeys' are creating an endless digital forest of mediocrity. They publish everything from uninformed political commentary, to unseemly home videos, to embarrassingly amateurish music, to unreadable poems, reviews, essays and novels".

It is fair to say that, even before Brabazon, there have been voices of concern like in [12] and [13], but those were more concerned about the power and misuse of search engines, and we will return to those aspects in Section 3. What Brabazon is mainly concerned about is that students are copying from the Web without even understanding what is being copied and that concentrated thinking is becoming impossible, due to an avalanche of distractions.

The term ADS (attention deficit syndrome) hardly existed a decade ago. Now, more and more children in schools are identified as having this syndrome, i.e. as being unable to sit still, concentrate on what is said or on some other coherent activity.

This is not just true for kids. In a way, our world is on the way to a "global attention deficit syndrome" (our terminology) due to the overwhelming avalanche of information that is bombarding us all the time: mobile phone, mail, tweets, chats, skyping, video-clips that are usually turned off if longer than 20 seconds (because we have become very impatient), we don't watch TV but channel-hop, internet pages 
with animated pictures, quivering links to attract attention, pop-ups all over the place, an audio clip when we move the mouse over some part of a page - unless we are listening to music with a plug in our ear, already. When we have to wait, we become restless. Rather than relaxing, we are trying to solve a Sudoku, etc. Seriously: When was the last time we did lean back and think concentrated without interruptions about our lives and what is good or wrong with them!

Our memory is failing, not because of Alzheimer, but because we don't practice it: we are not remembering phone numbers any more - why should we? We have a reminder function on our smart phone telling us about upcoming meetings; we do not know when we have the next three trips (it is all in our smart phone); we get lost if GPS does not work; if I misplace my smart phone I ring it up with the smart phone of my wife or friend, and then can easily locate it. (Too bad, I cannot ring my car keys yet, or my shoes, but this is bound to be possible anytime soon with smart tags).

Our thinking and observation suffer. Why should we worry about the rear end of our car, the distance warning peeping is all we need; we have a park assistant to park our car. Why should we worry about whether the change we get is correct when we pay: we use a credit card, anyway. Why the heck should we still be able to add a few numbers, or multiply two of them (let alone long division!) when we have a small calculator in our smart phone. Do we really still have to write when there is good speech recognition? Or, more basically, is correct spelling something we still need to know when our text processing software has an excellent spell-checker? Will we still read newspapers, when we can listen to them while driving to work (using not only the "common" mp3 recording of someone reading the paper professionally: even without human voice, new text to speech software is so good that it is hardly recognisable as computer generated). Surely this list can be continued arbitrarily!

Summarizing, the information flood created by new media and the possibility to get answers to just about anything through the Web is reducing our concentration, our ability to remember and to think clearly, is brainwashing us along the ideas of the main stream in whatever society we live in, and possibly makes much learning unnecessary. Putting it more positively, we are working more and more symbiotically with networked computers.

The main question is: how far can we go this way and still remain human? If we have to learn, why not be able to learn more efficiently using computers? Spitzer in [14] gives strong answers to this: that we are going too far, already. Learning (and keeping our brain as main computer) will always be necessary, and computers and media are more detrimental than helpful for the learning process.

"Computers in schools for teaching about biology are as important as it is to use bicycles for teaching how to swim", Spitzer writes, provocatively.

While Spitzer's book [14] appeared only in 2012, Bauerlein had his book [16] already published in 2008: "The dumbest generation ever; or: don't trust anyone below 30". It sharpens many of Brabazon's arguments, and is also quite sceptic about electronic media like Spitzer. One quote from his book, however, highlights an interesting observation that is very much worthwhile to consider: "Communication technology creates a barrier between generations. Young people have only one main aim: to be in". What Bauerlein basically says is that young people do not learn from their elders anymore, but from each other and the Web, thus (further) threatening cohesion between generations. To re-word one of his examples, 50 years ago a family with children would still have dinner together (at least in Europe), the children forced to listen to what the adults were discussing, and learning from them this way. Nowadays joint meals are rare. But if they do occur, while the parents are possibly talking, new SMS messages or tweets arrive, and it is now NECESSARY to look e.g. on the picture or the YouTube video clip, or else one cannot talk with friends about it, one cannot be "in".

\section{The Danger of Search Engines and Recommender Systems}

Some ten years ago, when Google started to dominate the search scene in many countries, a number of concerns were raised in publications like Weber 2006 [12], [17]-[20]: Nobody could vouch for the reliability of search results; why query-answers were ranked the way they were was often unclear: Google was, and is, not 
obliged to crawl all servers, nor is it impossible or illegal to adjust some rankings according to some criteria, including commercial interests or knowledge of who is querying or where a query comes from.

Weber formulated the danger that "We are googeling reality" [12] and Maurer has sharpened this to "We are googeling a reality as someone wants us to see it."

We all know that search engines collect information to establish user profiles. Email or chat services can extract information from our actions; cookies and similar devices can be used to analyze user behaviour; various social networks have become infamous for the fact how much they reveal about user; internet shops like Amazon use the information on what we have ordered before to recommend further items, etc.

A number of applications are tracking user behaviour on the Web. After all, advertising on pages with little traffic does not make sense! One of the best known engines for compiling statistics on the use of a website is Google Analytics. Even if we never explicitly use any services from Google, we are constantly in contact with Google applications, since more than $50 \%$ of all large servers (at least in Europe) have installed Google Analytics. How much personal information is extracted by Google Analytics and made available to Google for adding to personal profiles is not known.

Many of these services are a two-sided coin from which users also profit: after all, being shown new books or movies close to our taste may be quite convenient! The down side is that if everything we get from the Web is "personalized", then we are in a sense closed into a particular world, never seeing things outside it. It is a good lesson to carry out the same query with the same search engine on different computers in different locations: the (ranking of) results presented will be quite different. Again, even this is sometimes helpful. If I search for "Chinese restaurant" on a computer in London I am probably interested in restaurants different from the ones I find with a computer in Frankfurt. And - so we are assured - we can override such default options by searching "Chinese restaurant in $\mathrm{xxx}$ ", where $\mathrm{xxx}$ is the city we are interested in.

A serious complaint against many information providers is that information once posted can often not be recalled. However, this is also particularly true of search engines. Documents once indexed cannot be removed by authors in the sense that the search engine does not list them any more. This, together with photo-sites that do not allow the removal of pictures or other information can lead to unpleasant situations. Suppose X posted a photo with boyfriend $\mathrm{Y}$ at some stage, but now has a new boyfriend $Z$. X will not be excited that $Z$ can search for $X$ and still find the photo of her with Y. Similarly, a photo taken years ago and available on the net may be an obstacle to get a certain job, etc. Hence the usual advice to think hard what one posts on the Web should indeed be taken seriously. We often say: "Posting a picture on the Web is similar to getting a tattoo ... you may not like the looks of the tattoo on your wrinkly skin in 20 years time, but it will be close to impossible to get rid of it".

\section{Copy and Paste, and Plagiarism}

There are three entirely different angles to this. One is the concern that plagiarism is on the rise. This is due to the fact that writing an essay or seminar paper for a school or university assignment is now very easy by using a search engine to locate relevant literature and to use copy and paste. It is true that this is quite a problem in schools since a number of websites blatantly support this kind of process: sites like [21] offer full-fledged essays about just any school topic. The site [22] boasts that they can cover $200+$ topics from school to Ph.D. level. Although plagiarism detection software can help, see [23]-[25], it does not offer a full solution. Some software for scrambling an essay (e.g. using synonyms) making plagiarism detection harder is now also available; still more troublesome, plagiarism detection is virtually nonexistent across language boundaries: thus, some Japanese student may well take a top research paper from a university in the US, translate it into Japanese (or the other way around) and get away with it. Our recommendation is thus to use plagiarism detection software in schools (even searching for a random sentence in an essay may already give away the cheater); at research level it seems that only a systematically kept research diary, as suggested in Maurer et al. 2008 [25], offers real protection. 
A second concern is that Web sites are not reliable, as mentioned earlier. Hence just using the first best result given by a search engine might be outright dangerous: information may be wrong (the source and date are often not known) or ranking of search results may have been adjusted for commercial reasons. Looking at the first few entries of a search "boiling point of radium" using Google yielded 1737, 1430, 1140, and 1500 Centigrade! (Query May 3, 2013) Well, who cares about the boiling point of Radium? However, when I checked the edibility of one of my favourite fungi (Echter Ritterling) in 2012, I got "Very good eating" in one entry, yet "Deadly poisonous" in another. So here is a case where one can make a deadly mistake based on a query result! (Detailed investigations do indeed explain the discrepancies between the two contradictory statements. Yet this is exactly the point: one cannot believe query answers without detailed examination).

The third concern is that copy-paste is used by pupils and student to an extent that they do not even read, let alone understand the essay they are composing by gluing together snippets from various servers (mind you, some clever plagiarism detection algorithm may notice the change of style between parts of the essay.). Further, a survey with 300 students of economics and business administration revealed that more than $50 \%$ of the students are using social media in the search for scientific information, including searching in scientific wikis and blogs. For scientific wikis and blogs curated by so-called "citizen scientists", however, traditional quality assuring mechanisms, such as peer review, ceased to be valid; but pupils and students often consider content on the Web as being true and valid without any further reflection. It was in the book by Brabazon [9] who was the first to point out that copy-paste and short message systems like SMS or Twitter reduce the ability to read "with comprehension" and to write coherently, one of the strong (and indeed correct) arguments also offered by other authors including Spitzer [14].

Independent of whether we are concerned about plagiarism, it has become clear that essays written by students in schools are indeed most often not "written", but glued together by searching on the Web and then using copy/paste with a minimum of "filling" in between to yield a "new" essay. With the support of the Austrian Ministry of Science and Research we have tried to work with students age 11-17 within the socalled Sparkling Science Program to teach them alternatives [15]. Students can choose some topic they are interested in to write about. However, before doing so they have to consult the school library, search the Web for relevant material and pictures or other media clips they can use or link to (without violating copyrights) and they have to document what they have looked at, adding to their essay a list of "proper citations."

We define as a citeable item anything that is stable (i.e. does not change in time) and has a well defined source. For a paper or book, this may be the name of the authors with links to their biographies so readers can check the qualification of the authors. For other contributions, it may be some dictionary, archive, museum or some "trustworthy" website with information of some stability.

Although we did convince students that this is the proper way to write about some topic by first looking at previous efforts and analysing the topic from various points of view, we ran into two difficulties:

1. It was not clear what contributions on the Web satisfied our criteria for "proper citations". In particular, it was clear that contributions in Wikipedia do not qualify: except for citing particular versions (whose URLs are not trivial to access) there is no stability in time and the real author is not known. A contribution is often written by many, most using a pen-name, i.e. qualifications unknown. For this reason, a major source had to be the Austria-Forum [5] for which we give a brief description in the next but one paragraph.

2. Even more distressing was another phenomenon: although students would investigate various sources (as we determined by questions, i.e. not just relying on the list of references they provided), they did not write the essay with their own words, but ended up pasting together various bits and pieces from the sources identified, without substantial "creative writing". Thus the concerns mentioned in this paper that new media resources may undermine writing seem to be justified. We believe that much effort is needed to work against this trend.

For completeness sake, let us now briefly mention the main features of Austria-Forum as one 
of the reliable sources for citations. The AustriaForum is a special kind of encyclopaedia with a number of unique features:

- It concentrates on issues that have some connection to Austria or Austrians

- It is only concerned with contributions of some temporal stability (i.e. no information on current weather, sports, events, etc.)

- Most of its contributions are "frozen", i.e. do not change any more. This does, however, by no means imply that they will get obsolete sooner or later. Small corrections or additions in the form of comments (a feature provided by the system) can be made by any reader and are indeed welcome. However, the frozen contribution as such cannot be changed anymore, i.e. it behaves like a printed document. (This is what we are aiming for and it will be achieved to a large degree by mid-2014. Of the current 400.000 objects only about $50 \%$ are frozen); of course, an entry on some topic x might need a change some time: then a new contribution for $\mathrm{x}$ is added to the Austria-Forum, but the old one remains unchanged. The search in the Austria-Forum is carried out in such a way that a search for topic $\mathrm{x}$ always leads to the most recent entry on $x$, but this entry points to all previous ones. This is part of the extended version control of the Austria-Forum, a software that also handles not only new version, but new points of view on the same topic: if such a new point of view is inserted into the Austria-Forum, it is specified as such and ends up in what we call a "topic-list" with all other points of view on the same or related topic. The notion of topic-lists is also useful in other ways, since it allows a comprehensive collection of information on a topic, different from the piece-meal approach one often finds on the Web. Note that for some topics there will always be a current copy that is not frozen yet, like a description of a city which will clearly have to be updated once in a while. Whether a contribution is frozen immediately or "left open" for changes for some time depends on the item and editors involved.

- Multiple contributions on the same topic are welcome: "One cannot understand a complex issue unless one examines it from different points of view".
- Books are part of the Austria-Forum as "Web Books": when opened, they look like a printed book and pages can be turned; yet full-text searching is possible and, most importantly, links to other book pages or AustriaForum pages (and conversely) are possible, and metadata and comments can be attached to book pages.

- "Time travel" is possible: If you have found e.g. an entry on a city in Austria, you can move back in time, at least to those years (2003, 1995, 1996, 1955, 1938, 1915, 1902, 1835) where full-fledged encyclopaedias of Austria are available. Entries for years in between may well exist due to other historical documents, like the famous 62 volumes "Wurzbach" on Austrians (1881), or the famous book on poisonous plants (1871) or the handbook on Styria (1897).

- We integrate contributions from other sources (including Wikipedia) by "freezing" them and having an expert (whose name is then used in citations) to guarantee the quality of the entry.

\section{How does the Use of Web, of Computers and e-Learning Software Change Creativity?}

We first note again that the Web gives unprecedented easy access to information, both in textual, audio or visual forms. It thus is indeed clear that the Web has huge positive potential. The dangers seen by some, particularly if computers are used for teaching ("e-Learning"), is that information is used without checking for accuracy, that easy access discourages to remember facts and to think independently, and that many aspects of e-Learning are more distractive than helpful.

One of the most outspoken critics of e-Learning is certainly Manfred Spitzer [14] who goes to extremes, provocatively stating that computers are not only not helpful for learning, but are indeed endangering learning.

But before we go into some of the "against eLearning arguments" and what is true and what is not, it is fair to clarify in what way Spitzer objects to computers in schools: he of course agrees that students have to learn how to use computers for preparing talks, presentations, investigations on the Web, etc. And he does not 
object to teachers using networked computers in the classroom to show some experiment or interesting video clip. He does object, however, to the belief that 1) "the more media we use, the more students learn" and 2) it makes sense that all students should have their own tablet PC in the class and use it all the time.

Concerning 1), there are indeed books like [27] or papers like Maurer 2010 [26] that show that it is partially true. Media (including interactive ones) often distract and take up more time to convey some idea than is necessary. Let us give two examples: in teaching physics to students using computers, elaborate programs exist that allow to examine the parabola of e.g. an object thrown. After experimenting a long time, students will come to the right conclusion (or should we call it a guess?) that an object thrown at constant speed but varying angles travels the longest distance when thrown at an angle of 45 degrees. This is of course true, but a simple diagram with the formulae explaining what happens will take much less time, and the student then has the proof (instead of the guess) that 45 degrees are optimal. Similarly, videoand audio clips are much harder to navigate than text mixed with pictures: with video clips one often does have no alternative than to watch the laborious explanations; a combination of text/diagrams/pictures can be browsed more rapidly, depending on the reader, rather than at the speed of the video or audio clip. Extensive tests with over 10.000 students discussed in Hasebrook et al 2004 [27] show clearly the ambivalence of (too much and interactive) media in teaching: more is often NOT better.

Concerning 2), experiments the first author has been involved in by giving an iPad to each student in a class of e.g. 20 also support Spitzer to some extent: most teachers do lose control over a class when everyone is using such a device: some write email, others are in a chat, others play a game (and switch to another screen when the teacher is near them), etc. When teachers try to explain something they often get little attention. However, in some cases we also observed that teachers manage to give different tasks to students or groups of students and then students often work with enthusiasm and success. From our experience the verdict is still out if such classes will work in general or not: it depends much on the teachers, the students involved... and clearly teachers have to use completely new paradigms! And those paradigms (teacher training) have to precede giving a tablet $\mathrm{PC}$ to every student.

Spitzer very dramatically describes the decrease of the capability of memory due to new technology and he is not alone: Bauerlein and others are making the same statement (In a way this is reminiscent of Socrates who refused to learn how to write and read by claiming: "When someone starts to write, forgetfulness will overwhelm him." On the one hand, this is true: if we get the address of someone we will have to record it immediately, lest we forget it: with better memory training we could easily remember the address for ever. On the other hand, we would not even know about this statement of Socrates if his student Plato had not written it down).

As neuro-psychologist Spitzer has examined the part of the brain that is responsible for memory. He shows that this part is much larger in the brain of cabdrivers in London than of cabdrivers in Los Angeles. The reason seems to be clear: to become a cabdriver in London, you have to pass a very difficult test, knowing all streets, one-ways etc., i.e. you have to work on memorizing this information for months(!). In the process, the relevant area of the brain increases. In contrast, to become a cabdriver in Los Angeles, you only need a driver's license and a GPS.

However, Spitzer is not proving that cab drivers in London also remember other things better, or have a higher IQ or such. But even if this were the case, so what? Since we have devices that help us, why not use them? The average person hundred years ago was able to walk much longer with heavy loads than the average person today. Yet the average person today can move with still heavier loads both further and faster by just using a car.

We thus believe, and this is one of the most novel and provocative ideas in this paper, that we have to judge humans not just as biologically developed beings, but have to see them as symbiotic beings, part biological, part technical. To try to drive the point home, let us give examples.

The first author is nearly deaf (but he has good working hearing aids), he needs strong glasses to have good vision, has a pace-maker to keep his heart going and a titanium implant for one knee. With all this technology he is still able 
to act, work and enjoy life and the outdoors, including serious mountain hikes or SCUBA diving or the like. Take away the technology from him and he is at least a cripple, if not dead.

Or, if somebody is bad in calculating, remembering, in handwriting and in orientation, why should he not make up this with a bit of electronics for calculating, speech or keyboard input instead of writing (with fewer grammatical errors because of good spellchecking software) and a GPS for guidance. Note that modern smart phones provide most of those features and those and other features will migrate into devices like Google classes, intelligent wrist watches, or you just name it.

To put it again very strongly: do not judge a person without gear, whether it is tightly integrated or worn externally. I consider a person with a machine-gun as stronger adversary than mister universe, I consider a strong man with an axe very much inferior to a weaker one with a motor-saw, etc. So let us not overlook the fact that, yes, memorizing and some other features may have weakened humans (and will continue to do so), but with technology this is more than compensated: and we must look at the total capacity of a person with whatever technology is included, rather than ignore this.

A point that we have mentioned before and was first scientifically analysed in [5] is the fact that school children heavy into SMS, tweeting, chats and such, are doing worse in writing and comprehensive reading. Many authors provide further examples and warn that this is a phenomenon to be very much observed. We believe it is probably good to point out the consequences if we lose good creative writing and comprehending reading capabilities.

Yet it seems to us that the conclusive proof that reduction of the capability of creative writing also means that persons cannot express themselves as clearly any more when speaking, is missing; and so is the proof that not being able to read complicated text implies that we cannot understand complicated issues. To be more specific: we tend to believe that good writing and reading does indeed help us to communicate and understand well. However, it may also be that writing and reading are just crutches that we had to use for centuries, since we had no other way of recording information and knowledge. And that we are nearing the demise of written alphabetic language as we know it (in the Western world) in favour of other ways of recording and transferring knowledge, like using symbols, audio, video clips etc. We have done fairly extensive research on this in Camhy et al 2013 [28]-[29] and were able to show that, at least in some domains (like traffic rules), the use of symbols and video clips is quite superior to using written language. And let us not forget: if we buy furniture from IKEA for selfassembly, we get diagrams with no words at all!

Further universally accepted credos of even the strongest critics is that learning will remain an essential activity, but that computers might help less to ease the learning process than is sometimes assumed; but even if they did, it could be counter productive: serious learning means deep understanding and this can only happen in the human brain.

Most seem to agree that learning as activity will remain, and will be necessary to make sure that our "muscle" brain does not degenerate as much as the muscles in our arms have after we stopped chopping wood. Some computer scientists believe that future humans will live symbiotically with computer networks quite well. Let us state once more and very radically: even if our brain degenerates, if we, together with computers, are more clever than before, what is wrong about this?

However, let us assume with the majority of scientists that learning (logical thinking and certainly also memorizing some facts) will remain an important activity. Then a burning question is: what are the important things we have to learn? Probably not arithmetic (we have relegated this to calculators years ago); probably not spelling (we leave this to spell checkers); probably not handwriting (we are inputting text now mainly using keyboards); probably not the basics of foreign languages (this will be replaced by translation programs, unless we want to dig very deep into a specific culture); probably not how to construct triangles or other geometric problems (the argument that this is good for learning logical thinking is weak, since learning how to play chess would do the same and be more fun for most of us); etc. Thus, a rethinking of what to teach is probably more important than the question of how we teach.

We often hear that among the new things we have to teach are computer skills and how to 
use the Web (we agree on this). However, it is surprising to us that crucial aspects of our life are currently mostly excluded from teaching in schools: why do we teach about the geography of some remote corner of the world, as is usually found in curricula of schools (at least in Europe), but medicine and health are not covered, yet clearly they are more important for our lives. Similarly, how come we teach much about "old" history, and little on recent history or political issues; or why do we not teach childcare and how to bring up children (is this not THE most important job in our lives?); and how about learning how to make sure that partnerships last and if not, how to avoid "rose wars" at the end?

Those topics seem to us of paramount importance, yet critics of computers tend to ignore them in favour of negative comments about new technology. It is true that no e-Learning environment has ever been proven to be superior to good old-fashioned teaching and tutoring on a large scale. The hype that "universities become unnecessary because of e-Learning" is as unjustified as the hype a few hundred years ago that "the printing press will make universities obsolete". Yet we must not ignore the fact that printed books are useful for education in some cases, and some aspects of the Web are, if they are well done and used where it makes sense: because of time or location constraints; on the job when needed; as preparation for some course or activity; as repetition of material learnt earlier; to catch up with missed material because of illness, or whatever; etc.

Maybe one aspect does deserve serious thinking. To truly understand something, we have to "rack our brain" as much as we have to sweat and exercise a lot if we want to be good in some sports activity. This is certainly true to some extent: when good teachers explain some difficult material, they sometimes use tricks, pretending to falter, or they make mistakes that they then correct: all to show to the students that there is a difficulty. Other teachers might hide the same difficulties by eloquently passing over them, leaving the students with no feeling for the real problem behind the nice speech and diagrams. "Bad" teachers are not necessarily bad for students: because students did not understand what was explained, they have to consult other sources and eventually work out what is needed on their own, in the process getting a very good feeling for the problem.
Yes, it is somewhat discouraging that there is little correlation between the quality of teaching and the quality of learning. This also applies to the Web in general: maybe it is good that not all we find on the Web is perfect, since this is the reason we learn (hopefully) to use it with care and cross-checking whatever we find. If we achieve by new techniques a high degree of curiosity and enjoy the process of getting new knowledge from the Web - much like a good sports trainer manages to make us work hard on some physical skills and still like it, we have reached a lot and the Web can indeed help creativity rather than stifle it.

\section{Conclusion}

We have discussed at some length positive and negative effects of the Web and tried to show that many negative ones disappear if one accepts that we are more and more living in symbiosis with technology. However, we have not discussed whether we indeed want such a symbiosis. The answer to this is two-fold: first, such a symbiosis is beneficial if it retains our individual personality and, most important, does not make us entirely dependent on the technology at issue, i.e. systems must have enough redundancy to overcome dramatic breakdowns; second, we do not have much choice: with world population still growing, and peaking (if we are lucky) at 12 billion, there is no way to provide a reasonable standard for all people without further improving (not just ICT) technologies.

Summarizing the gist of this paper, we have argued that we must watch out that the Web does not stifle creativity: it does have some potential for this - but also for helping creativity. Most important, to use some dangers as excuse to damn the Web, e-Learning, computers and other technologies is very dangerous: it ignores that some developments may not be beneficial, yet others are. Yes, there are dangers inherent in the Web, like we elaborate in [1] or [31]-[34], but to state over and over again that all innovation coming through the Web is bad will just be an excuse for those who are too lazy to seriously look at innovative approaches, as Dueck points out in his beautiful paper [35] and it should be clear to all of us that innovation is the key for our future. 


\section{References}

[1] H. MAurer, K. TOCHTERMAnN, Is the Internet turning us into dummies. Presented in the Proceedings of ED-MEDIA Conference (2013), Jan Herrington et al. (Eds.), Chesapeake, VA, AACE; pp. 2524-2534

[2] http://www.britannica.com/

[3] http://www.brockhaus.de/buecher/erwachsene/brockhaus_enzyklopaedie/online.php

[4] www.brockhaus-enzyklopaedie.de/

[5] austria-forum.org

[6] www.serbia-forum.org

[7] http://www.si.edu/encyclopedia

[8] http://openlibrary.org/

[9] T. BRABAZON, The University of Google. Ashgate, 2007.

[10] J. SUROWIECKI, The wisdom of Crowds. Anchor Books, 2005.

[11] A. KeEn, The cult of the amateur. Double Day, 2007.

[12] St. Weber, The Copy-Paste Syndrom. TeleopolisHeine, 2006.

[13] H. Maurer, F. Kappe, B. ZaKa, Plagiarism - A Survey. J. UCS, 12(8) (2006), 1050-1084.

[14] M. SPITZER, Digitale Demenz. Wie wir uns und unsere Kinder um den Verstand bringen. Roemer Verlag, 2012. [Approximate English translation: Digital Dementia: How we ruin the brains of us and our children].

[15] http://austria-forum.org/af/SparklingScience

[16] M. BAUERLEIN, The dumbest generation. Paperback and available on Kindle, 2008.

[17] G. REISCHL, Die Google Falle. Ueberreuter, 2008.

[18] G. CoNT, Googling Considered Harmful. New Security Paradigms Workshop '06, September 2007, $18-21$.

2006, Schloss Dagstuhl, Germany. Copyright 2006 ACM, see http://www.iicm.edu/GooglingConsidered_Harmful.pdf

[19] H. MAURER, Google-Freund oder Feind? Informatik Spektrum, 30(4) (2007), 272-278. http://www.iicm.tugraz.at/papers/ google_freund_oder_feind.doc

[20] N. Kulathuramaiyer, W. T. Balke, Restricting the View and Connecting the Dots. Dangers of a Web Search Engine Monopoly. J. UCS, 12(12) (2006), 1731-1740

[21] http://www.e-hausaufgaben.de

[22] http://www.tutionster.com/
[23] H. MAURER, B. ZAKA, Plagiarism - a problem and how to fight it. Proc. of ED-MEDIA 07, (2007), Vancouver, Canada, AACE.

[24] N. Kulathuramaiyer, H. Maurer, Fighting plagiarism and IPR violation: why it is so important? Learned Publishing, 20(4) (2007), 252-258.

[25] H. Maurer, N. Kulathuramaiyer, Learning Ecosystems for Dealing with the Copy-Paste Syndrome. Journal for Research in Innovative Teaching, 1(1) (2008), 1-25.

[26] H. MAURER, Unforseen Effects of the WWW. Journal of IT in Asia, 3(1) (2010), 3-11.

[27] J. P. Hasebrook, H. Maurer, Learning Support Systems for Organizational Learning. World Scientific, London/Singapore, 2004.

[28] D. G. Camhy, H. Maurer, R. Stubenrauch, Foundations of MIRACLE: Multimedia Information Repository, A Computer-supported Language Effort. JUCS, 9(4) (2003), 309-348.

Electronic version: http://www.jucs.org/jucs _9_4/foundations_of_miracle_multimedia

[29] D. G. Camhy, J. A. Lennon, H. Maurer, R. STUBENRAUCH, Applications of MIRACLE: Working With Dynamic Visual Information. JUCS, 9(4) (2003), 349-368.

Electronic versions: http: //www.jucs.org/ jucs_9_ 4/applications_of_miracle_ working

[30] J. A. LENNON, H. MAURER, MUSLI: A hypermedia interface for dynamic, interactive and symbolic communication. JNCA, 24(4) (2001), 273-292.

[31] D. BRIN, The Transparent Society- Will Technology Force Us to Choose Between Privacy and Freedom? Basic Books, 1999.

[32] O. LEE, Waiving Our Rights: The Personal Data Collection Industry and Its Threat to Privacy and Civil Liberties. Rowman \& Littlefield, 2011.

[33] L. ANDREwS, I Know Who You Are and I Saw What You Did: Social Networks and the Death of Privacy. Free Press, 2012.

[34] CH. Schertz, D. Hoech, Privat war gestern- Wie Medien und Internet unsere Werte zerstoeren. Ullstein Verlag, 2011.

[35] G. DUECK, Wildes Wunschkind Innovation. Informatik Spektrum, 36(1) (2013), 1004-1010. 


\author{
Contact addresses: \\ Hermann Maurer \\ Graz University of Technology \\ Inffeldgasse $16 \mathrm{c}$ \\ A- $8010 \mathrm{Graz}$ \\ Austria \\ e-mail: hmaurer@iicm.edu \\ Rizwan Mehmood \\ Graz University of Technology \\ Inffeldgasse $16 \mathrm{c}$ \\ A- $8010 \mathrm{Graz}$ \\ Austria \\ e-mail: rmehmood@iicm.tugraz.ac.at \\ Petra Korica-Pehser \\ Graz University of Technology \\ Inffeldgasse $16 \mathrm{c}$ \\ A- $8010 \mathrm{Graz}$ \\ Austria \\ e-mail: pkorica@gmail.com
}

HERMANN MAURER is Emeritus Full Professor from the Graz University of Technology where he has been Chair or vice-Chair of the Institute for Information Systems and Computer Media since 1988. He was co-founder and chairman of the board of the Hyperwave AG Munich 1997-2005, and vice-chairman of same company till 2009; founder, and later scientific advisor of the first research center on knowledge management in Austria.

Prof. Maurer received a number of awards, among them the "Austrian Cross of Honours for Arts and Science Class I". He received Honorary Doctorates from the Polytechnical University of St. Petersburg, the University Karlsruhe, Germany, and the University of Calgary, Canada.

Hermann Maurer is author of twenty books, over 700 papers in various publications, founder and Editor-in-Chief of 'Journal of Universal Computer Science' till the end of 2011, Co-Editor of 'Journal of Research in Innovative Teaching' and member of over a dozen editorial boards. He founded the conference series ED-MEDIA and WebNet/eLearn and the conference I-KNOW; he was a European Representative at ICCE till 2000 .

He was responsible for the development of the first second generation Web Based Information System Hyperwave, and Learning Suite, a modern net based teaching platform, and a large electronic encyclopaedia Austria-Forum that in its first version has some 400.000 entries per February 2013

Prof. Maurer has given over 1000 talks on various occasions, including many as invited or keynote speaker at international conferences. He has been an outspoken critic of some data-mining activities in the WWW. He worked in a variety of areas including applications of computers to exhibitions and museums, Web based learning environments, languages and their applications, data structures and their efficient use, telematic services, computer networks, computer supported new media, dynamic symbolic language and techniques to fight plagiarism. His current main research and project areas are networked multimedia/hypermedia systems; electronic publishing and applications thereof, information integration, future implications of computers, and computers in Science Fiction.
RIZWAN MEHMOOD started his professional career as a Software Engineer. He joined Makabu (a leading software company in Pakistan) in 2005 and was involved in the development and design of many desktop and web applications. He provided his services to Aspire solutions afterwards and designed various static and dynamic web applications. He joined ERRA (a public sector organization which was developed to monitor the projects after the disastrous earthquake in Pakistan) as system analyst in August 2007 and supervised the data engineering group. He worked as Research Associate in NUST (National University of Science and Technology) for two years.

He did his Masters in Information Technology(MS-IT) from NUST. He is currently PhD student at the Graz University of Technology He is the author of two papers and member of the software development team of Austria Forum.

Main research and project areas:

Information architecture, multimedia information systems, Web based learning; languages; artificial intelligence; information retrieval; Web 2.0; semantic Web; database.

PETRA KORICA-PEHSERL Study of Software Development and Management at the Graz University of Technology (Austria) starting in 2003. Candidate for Ph.D. in Computer Science from the Graz University of Technology in 2014. Working at Microsoft in Vienna (Austria), Paris (France) and Zagreb (Croatia) since 2009.

She is author of fifteen papers and member of the Editorial Board of Austria Forum. So far Petra has held more than 30 presentations on conferences worldwide.

Main research and project areas:

Web based learning; languages; artificial intelligence; robotics; computer vision; information retrieval; Web 2.0; semantic Web; data; cloud computing. 